\title{
Internet, utopía o panóptico de la Sociedad de la Información
}

\author{
Por Octavio IsLas y \\ FERnANDo GutiérRez
}

\section{La "Sociedad de la información"}

En los años recientes, el término "Sociedad de la Información" ha sido incorporado en los discursos político, académico y mediático contemporáneos, para designar al proyecto de sociedades posibles del nuevo milenio, en las cuales serán empleadas intensamente las avanzadas tecnologías de información -particularmente las asociadas con el desarrollo de Internet-, a través de las cuales circulará una gran cantidad de información relevante para el consumo cultural de estas sociedades.

Una de las principales características de nuestros "nuevos tiempos modernos" efectivamente es la velocidad con la cual la información se genera, transmite y procesa. Hoy es posible conseguir ínformación de forma inmediata, y en no pocas ocasiones inclusive es posible obtenerla a partir de la misma fuente que la produce, trascendiendo fronteras y limitantes de espacio y temporalidad. Es posible afirmar que el desarrollo de Internet ha transformado un amplio número de prácticas informativas. En la década de 1980, por ejemplo, los responsables de la comunicación social de la Presidencia de la República giraban las instrucciones pertinentes para incautar, en el Aeropuerto Benito Juárez de la Ciudad de México, todos los

${ }^{1}$ Octavio Islas estudió la licenciatura en Sociología en la Universidad Autónoma Metropolitana; la maestría en Comunicación y Desarrollo en la Universidad Iberoamericana; la maestría en Administración de Tecnología de la Información en el Tecnológico de Monterrey; y el doctorado en Ciencias Sociales en la Universidad La Salle. Fernando Gutiérrez estudió la licenciatura en Comunicación, la maestría en Administración de Tecnologías de Información, y la maestría en Comercio Electrónico en el Tecnológico de Monterrey. Ambos investigadores, adscritos al Proyecto Internet del Proyecto Internet del Tecnológico de Monterrey, Campus Estado de México, coordinan la Cátedra de Comunicaciones Estratégicas y Cibercultura. Sus correos electrónicos son: octavio.islas@itesm.mx y fgutien@itesm.mx 
ejemplares de cualquier periódico extranjero"cuyo contenido pudiera incluir alguna nota desfavorable a la imagen del presidente en turno. Evidentemente el volumen y la variedad de la información que cada día circulan en Internet, han convertido en figuras anacrónicas a muchos de los celosos censores de antaño.

A pesar del formidable desarrollo de Internet, desafortunadamente sólo un reducido porcentaje de la población mundial hoy disfruta de las beneficios que supone la "Sociedad de la Información y el Conocimiento". En México, por ejemplo, de acuerdo con una investigación realizada por la firma Select-México -posiblemente la más reconocida en materia de investigación estadística de Internet en México-, el número de usuarios frecuentes de Internet asciende a poco más de 10 millones de usuarios, y se estima que al concluir el año 2003, el total de cibernautas será de 12 millones. La concentración de los usuarios de Internet en el territorio nacional es la siguiente:

Figura 1 Porcentaje de usuarios de Internet y su distribución en el territorio nacional

\section{$\%$ Usuarios de Internet}

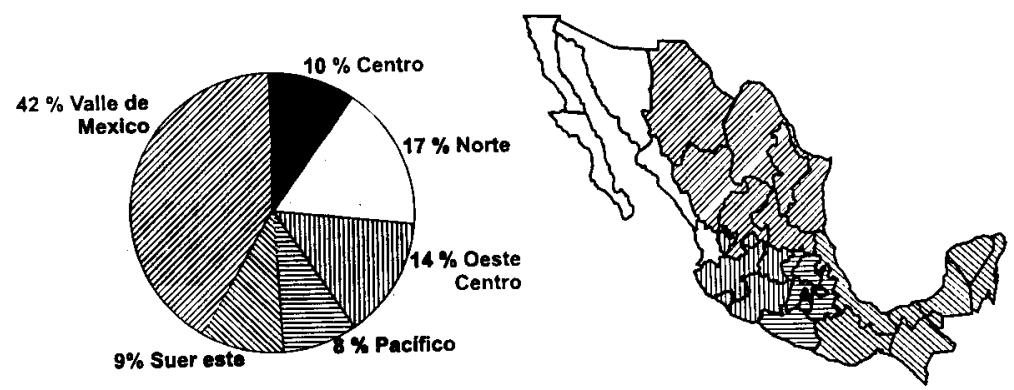

Fuente: Select México: "Panorama de los usuarios de Internet en México 2002".

http://www.select.com.mx

${ }^{2}$ Véase J Garcés y F. Cruz: Panorama de los usuarios de Internet en México 2002. Disponible en línea en: http://www.select.com,mx Fecha de consulta: 28 de agosto, 2003. 
De acuerdo con Rafael Pascuet, el sistema teeno-económico de la sociedad de la información no corresponde a una geografía de países, sino de redes. Redes de información y tecnología que incluyen o excluyen a personas, empresas, ciudades, regiones o áreas de ciudades y regiones, según el valor que tengan desde el punto de vista del sistema económico. Si aceptamos que Internet representa la columna vertebral de la "Sociedad de la Información y el Conocimiento", la asignatura pendiente consiste en procurar la efectiva masificación del "medio inteligente", con el propósito de que amplias capas de la sociedad disfruten de los beneficios que se suponen inherentes a la "Sociedad de la Información".

La llamada "brecha digital" que separa a los países en vías de desarrollo de las naciones del llamado "primer mundo", podría profundizar aún más las sensibles diferencias que persisten entre los ciudadanos de las economías desarrolladas de quienes vivimos en países que se encuentran en vías de desarrollo. Los países que se rezaguen en la adopción de las innovaciones tecnológicas -concluye un informe de Naciones Unidas-, definitivamente correrán el peligro de verse marginados por aquellas naciones en las cuales el inteligente empleo de las nuevas tecnologías han otorgado una ventaja competitiva.

Hoy Internet es la red pública más grande del mundo, y el número aproximado de usuarios, de acuerdo con datos del 2002, ascendía a más de 600 millones de personas en más de 170 países. ${ }^{4}$ Nuestra siguiente tabla nos permitirá reconocer la concentración mundial de los usuarios de Internet:

Tabla 1 Número de usuarios de Internet por región (Septiembre, 2002)

En las naciones en vías de desarrollo aún se observa una limitada participación en Internet. Por esa razón algunos gobiernos han emprendido determinados programas para enfrentar los retos que impone el tránsito a la sociedad de la información. En México, por

${ }^{3}$ Véase R. Pascuet : Manuel Castells. El cartógrafo de la aldea global. Disponible en línea en: http://www,fundaciocampalans.com/frc/ tex titol.cfm?ID=10 Fecha de consulta: 28 de agosto, 2003.

${ }^{4}$ Véase NUA Internet Surveys: How Many Online Disponible en línea en: http://www.nua.com/surveys/how many online/ Fecha de consulta: 28 de agosto, 2003. 


\begin{tabular}{|ll|}
\hline \multicolumn{2}{|c|}{ Número de usuarios de Internet por región } \\
\hline Total de usuarios en Internet \\
605,60 millones \\
África & Medio Oriente \\
6.31 millones & 5.12 millones \\
& \\
Asia / Pacífico & Canadá y Estados Unidos \\
187.24 millones & 182.67 millones \\
& América Latina \\
Europa & 33.35 millones \\
190.91 millones & \\
\hline
\end{tabular}

Fuente: NUA Internet Surveys.

http://www.nua.com/surveys/how many onlinel

ejemplo, el gobierno del presidente Vicente Fox Quezada delegó en la Secretaría de Comunicaciones y Transportes el desarrollo del Sistema Nacional e-México, el cual:

"consiste en llevar a cabo todas las acciones necesarias para que los ciudadanos, las comunidades y las regiones del país vivan dentro de una nueva estructura de organización social, la sociedad de la información y el conocimiento; para que todos los mexicanos se desarrollen en un entorno de igualdad de oportunidades de acceso al conocimiento, el aprendizaje y la educación a través del uso y aprovechamiento inteligente de las nuevas tecnologías, las cuales deben de estar al servicio de la sociedad para conducir de manera efectiva la transición del país hacia el apropiamiento de los servicios digitales para el ciudadano del siglo XXI".

Según el informe La Sociedad de la Información en España, 2002, documento que fue elaborado por algunos expertos de la empresa Telefónica de España, la Sociedad de la Información: "en realidad se trata todavía de un terreno poco firme, con nuevos conceptos que no están suficientemente asentados, con la carencia de un modelo

\footnotetext{
${ }^{5}$ Véase: http://www.sct.gob.mx
} 


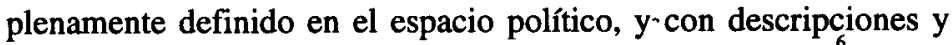
análisis globales que en ocasiones resultan contradictorios".

En América Latina no pocos de los investigadores que anteriormente objetaban la posibilidad de reconocer a Internet como medio de comunicación, hoy se presentan a sí mismos como expertos en el tema de la "Sociedad de la Información y el Conocimiento". De acuerdo con la destacada investigadora Claudia Benassini Félix, investigadora de la Cátedra de Comunicaciones Estratégicas del Tecnológico de Monterrey, Campus Estado de México, a Daniel Bell corresponde el mérito de haber introducido el concepto "Sociedad de la Información".

Es justo reconocer que algunos de los aspectos medulares de la llamada "Sociedad de la Información", fueron abordados con gran oportunidad por reconocidos analistas del fenómeno del cambio tecnológico, como Marshall McLuhan, Harold Innis, Neil Postman quien falleció en el mes de septiembre-, y Walter Ong -entre otros-. En La Tercera Ola, Alvin Toffler, por ejemplo, anticipó con singular claridad el advenimiento de "La Sociedad de la Información". De acuerdo con Toffler, hace más de 10,000 años la agricultura "la Primera Ola" introdujo cambios trascendentales en la historia. No sin enfrentar profundas dificultades, en la "Primera Ola" los primitivos cazadores y recolectores transformaron sus condiciones de vida al formar las primeras sociedades de campesinos, en las cuales la productividad dependió del formidable despliegue de la fuerza humana, la fuerza animal, el sol, el viento y el agua. Quienes oportunamente comprendieron que las nuevas organizaciones sociales estarían centradas en el campo evidentemente resultaron beneficiados.

En "la Segunda Ola", las revoluciones industriales desencadenaron profundos cambios en la historia, dando lugar a un nuevo tipo de civilización, centrada en la industria y la producción a gran escala. La productividad empezó a depender en la relación que los hombres establecieron con las máquinas. Amplios contingentes humanos abandonaron el campo para desplazarse a las ciudades.

De acuerdo con Alvin Toffler, la "Tercera Ola" introducirá una nueva sociedad, la cual descansará en la información, el conocimiento

${ }^{6}$ Véase "La Sociedad de la Información en España, 2002". Disponible en línea en: http://www.telefonica.es/sociedaddelainformacion/espana2002/partes/ intro/index.html Fecha de consulta: 28 de agosto, 2003. 
y la creatividad. En las sociedades de la "Tercera Ola", la productividad dependerá del desarrollo de nuevas tecnologías, las cuales -afirma Toffler- permitirán al hombre hacer menos y pensar más.

Siguiendo los pasos de Toffler, el destacado investigador español Javier Echeverría, afirma que el desarrollo de las avanzadas tecnologías de información y comunicaciones, contribuye a configurar un nuevo espacio social, al cual designa como "el tercer entorno". A continuación enunciaremos algunas de las principales características del "tercer entorno":

Tabla 2 Principales atributos de los tres entornos

\begin{tabular}{|lll|}
\hline Primer entorno & Segundo entorno & Tercer entorno \\
\hline Physis & Polis & Telépolis \\
Natural & Urbano & Telemático \\
Sociedad agraria & Sociedad industrial & Infosociedad \\
Educación familiar & Escuela & Educación virtual \\
Aldea & Barrio y ciudad & Comunidades virtuales \\
& & \\
\hline
\end{tabular}

Fuente: Javier Echeverría.

Los medios de comunicación masiva se han desempeñado como efectivas palancas históricas del desarrollo cultural de las sociedades de la "Segunda Ola", y es posible considerar a la televisión como el medios de comunicación masiva más importante de las sociedades de la "Segunda Ola". En el "Segundo Encuentro Mundial de Comunicación", evento que fue organizado por Televisa, en julio de 1979, en Acapulco, Guerrero, el destacado comunicólogo Wilbur Schramm, afirmó que el siglo XX admitía ser designado como la "Edad de la Televisión", particularmente a partir del 26 de enero de 1926, fecha en la cual John L.Baird, pionero de la televisión mecánica, realizó la primera demostración pública de la televisión a los miembros de la "Royal Society".

${ }^{7}$ Conferencia dictada por Javier Echeverría en el marco del Seminario Internacional en Comunicación y Desarrollo "La construcción Global de la Información", Sevilla, España, 24 de octubre de 2001. 
En México, desde comienzos de la década de 1950, la industria televisiva nacional ha incidido de forma categórica en el proceso de modernización de nuestra sociedad. Sobre el sentido y los alcances de la contribución cultural de la llamada «ventana electrónica», el historiador Héctor Aguilar Camín (1989), afirma:

«La televisión ha sido el mayor cambio cultural de la sociedad mexicana en los últimos treinta años; ha desplazado al cine como surtidor de la mitología popular ya ha erigido un ámbito propio de valores. Ha roto y replanteado los vínculos de la sociedad con el pasado, ha instaurado una pedagogía sentimental y un nuevo contenido del ocio: Ha hecho aparecer una cultura masiva, una geografía mental que es pareja insustituible de la modernización. Y ha roto el aislamiento de pueblos y regiones entre sí, y de México con el mundo (...) la televisión es una actividad de punta (...) ha sido el medio más eficaz para unificar la conciencia y el consumo del país. Su expansión ha creado una zona compartida de experiencia nacional. Lo que sucede en la televisión sucede para más mexicanos que ningún otro acontecimiento. Es la máquina que homogeneiza los hechos y la percepción de los hechos. El imperio de la televisión ha roto también el aislamiento provinciano; propicio a la inmovilidad y al claustro, así como la reiteración desinformada de rutinas y valores. Ha conferido un carácter masivo a la internacionalización de la información hasta provocar lo que McLuhan juzgó en los setentas como una bomba de tiempo: la revolución de las expectativas locales por la difusión de los patrones de consumo del mundo desarrollado. La televisión es también un termómetro que define los criterios de lo anacrónico y lo moderno. En ella se verifica una ruptura severa, aunque no escandalosa, con los valores de la sociedad tradicional. Las realidades rurales y regionales apenas existen en el mundo televisivo. Su terreno es el de la innovación y la moda. Construye los personajes y aficiones de la cultura popular, la guía del consumo, los contenidos de la educación informal, los escaparates de la vida deseable. Es la franja que fija también, poco a poco, por acumulación de años, los valores familiares. Su rara simbiosis de medio hogareño y vanguardia modernizadora cuestiona a fondo la moral heredada - catolica, preurbana, provinciana - sin entrar en pleitos frontales con ella. El proceso es claro en la evolución de los sentimientos permitidos en el género familiar por excelencia, la telenovela. Se propagan 
ahí transgresiones argumentales a núcleos básicos de la moral familiar imperante (...) La televisión mexicana ha sido portadora de un conjunto de valores y conductas cuya intención final sería, según Carlos Monsiváis, promover algo así como una «eficacia dócil», que modernice sin romper, cambie sin agitar, triunfe sin rebelarse ni cuestionar lo establecido». ${ }^{8}$

Nuestros días corresponden al tránsito de la llamada «Edad de la Televisión» hacia aquello que admitiría ser designado como «La Edad de Internet». En "La Edad de Internet" paulatinamente emerge un nuevo tipo de sociedad: "La Sociedad de la Información y el Conocimiento", la cual, con el paso de los años podría contribuir a conformar un nuevo tipo de contrato social. Es difícil estimar cuánto tiempo tomará la transición de la "Edad de la Televisión" a la "Edad de Internet". Sin embargo, es posible anticipar la inevitable fusión de los referidos medios, la cual fue anticipada con gran claridad por Nicolas Negroponte (1996).

De acuerdo con Alvin Toffler, la "desmasificación" representa la principal característica de los medios de comunicación propios de la "Tercera Ola". Internet efectivamente no es un medio de comunicación masiva -por tal motivo algunos comunicólogos concluían que Internet definitivamente no admitía ser considerado como medio de comunicación-. Internet, sin embargo, es el medio de comunicación "nativo" de la "Tercera Ola", pues además de ser un medio eminentemente "desmasificador", produce y reproduce (Lühmann) entornos inteligentes. Internet es el medio de comunicación "inteligente" que expresa, en su admirable complejidad y perfección, el sentido más amplio de lo que representa en nuestros días la convergencia tecnológica, instalándonos en una especie de versión más avanzada de aquello que Marshall McLuhan acertó en designar como la "aldea global".

La convergencia digital que desplaza consigo el desarrollo de Internet, incide definitivamente en las posibilidades de innovación de industrias como la informática, la electrónica de consumo doméstico, la robótica, la microelectrónica, la multimedia, los medios de comunicación, las telecomunicaciones y la realidad virtual, entre

\footnotetext{
${ }^{8}$ Véase H. Aguilar Camín (1989): Después del milagro. México. Editorial Cal y Arena. Páginas 245-247.
} 
otras. La ruta de innovación tecnológica que hoy siguen las referidas industrias, definitivamente se encuentra estrechamente asociada con el desarrollo de las herramientas de comunicaciones de Internet. La convergencia digital parece ser un proceso irreversible.

En el concepto "La Sociedad de la Información" subyacen tres elementos de singular relevancia: sociedad, estructura y entorno. Reparemos brevemente en ellos. El primero (sociedad), involucra a los agentes (individuos), quienes son los usuarios de las avanzadas tecnologías de información. El segundo (estructura), comprende los recursos tecnológicos y los contenidos almacenados. El tercero (entorno), corresponde a diversos ámbitos, por ejemplo: económicos, políticos, educativos, culturales, etcétera, los cuales admiten profundas reconfiguraciones tras la composición de una estructura particular representada por una nueva tecnología de comunicación e información (Internet).

El desarrollo de Internet ha modificado la concepción del trabajo, las posibilidades de información y entretenimiento, los sistemas de educación, un amplio número de actividades comerciales e inclusive políticas. La incorporación de Internet en el mundo de los negocios ha propiciado profundos cambios ecológicos, como por ejemplo, el tránsito de la oficina convencional a la oficina móvil; el paso del trabajo convencional que se realiza en las oficinas al teletrabajo; la metamorfosis del gobierno convencional al gobierno digital; la reconversion de las tiendas tradicionales en las plazas virtuales.

Podemos concluir que el término "Sociedad de la Información" efectivamente permite designar el posible advenimiento de una nueva forma de organización de la economía y la sociedad, la cual descansa en la incorporación y el inteligente empleo de las avanzadas tecnologías de información, las cuales se encuentran subordinadas al propósito de producir nuevas formas de conocimiento. Manuel Castells (1997), a quien algunos de sus críticos califican como un "pragmático optimista", afirma que la sociedad de la información: "es un nuevo sistema tecnologico, económico y social. Una economía en la que el incremento de productividad no depende del incremento cuantitativo de los factores de producción (capital, trabajo, recursos naturales), sino de la aplicación de conocimientos e información a la gestión, producción y distribución, tanto en los procesos como en los productos". 


\section{Internet, utopía o panóptico de la sociedad de la información}

La lectura optimista de la utopía "Sociedad de la Información" efectivamente nos permite concebir nuevas posibilidades de liberación que el mismísimo Herbert Marcuse hubiese reconocido y elogiado. En cambio, una lectura pesimista nos obligaría a reparar en los evidentes renglones de exclusión, así como en el perturbador despliegue de avanzados dispositivos panópticos (Foucault), capaces de ejercer funciones de vigilancia y castigo al detalle.

La formidable participación e interactividad que observan los usuarios de Internet, representa una cualidad que se proyecta como perfecta antítesis del conformismo y de la «pasividad dirigida» que abruma y paraliza a los receptores de los medios de difusión convencionales. De acuerdo con Noam Chomsky (1997) los propietarios de los medios de difusión colectiva: «no desean gente que tome decisiones o participe; quieren una población de consumidores y espectadores políticos pasivos y obedientes; una comunidad tan atomizada y aislada que le resulte imposible reunir sus limitados recursos para convertirse en una fuerza independiente, poderosa que denuncie la concentración de poder».

A diferencia de "la pasividad dirigida" que padecen los receptores de los medios de difusión convencionales, los usuarios de Internet se distinguen por su intensa participación en todo tipo de asuntos públicos. Internet -medio nativo de la Tercera Ola- contribuye a desplazar la "mente postuniformizada". Además Internet es un medio de comunicación que efectivamente permite afirmar y promover la diversidad. La intensa interactividad de los usuarios de Internet les permite desempeñar funciones comunicativas que anteriormente representaban indisputables privilegios de determinadas instituciones.

La pluralidad temática y discursiva que aún prevalece en Internet, contrasta notablemente con la «unidireccionalidad discursiva» que promueven los medios de difusión convencionales. Mientras que en los medios convencionales la propiedad generalmente determina los posibles contenidos, en Internet prevalecen la apertura, la diversidad y la universalidad temática. Evidentemente muchos de los contenidos y temas que son tratados en Internet desbordan los límites de

9 En el capítulo XIX de La Tercera Ola (Descifrando las nuevas reglas), Alvin Toffler aborda el tema en el apartado "la mente postuniformizada". 
permisibilidad y tolerancia que han establecido la mayoría de propietarios o concesionarios de los medios de difusión masiva convencionales. Los usuarios de Internet definitivamente no se ajustan a las pautas de conformismo y control social que han impuesto los medios de difusión convencionales en sus receptores.

Es posible afirmar que los lamentables acontecimientos del 11 de septiembre de 2001 transformaron radicalmente el panorama de la "Sociedad de la Información y el Conocimiento". La deseable transición hacia una economía mundial fincada en el desarrollo de "la Sociedad de la Información y el Conocimiento" parece haber quedado en suspenso. George W. Bush, el cuadragésimo tercer presidente de la llamada "república imperial", decidió apuntalar su gestión presidencial en dos actividades que de ninguna manera resultan ajenos a los intereses de su acaudalada e influyente familia: la economía de guerra y el negocio del petróleo.

El 11 de septiembre del 2001, la opinión pública internacional contempló la dramática vulnerabilidad que exhibieron los sistemas de seguridad y defensa del gobierno de Estados Unidos. A partir de ese día las relaciones entre el gobierno del presidente Bush y los principales medios informativos de la Unión Americana cambiaron radicalmente. En esa nación los valores que supone el ejercicio del periodismo profesional entraron en contradicción frente a los argumentos relativos a las necesidades de seguridad nacional que pregona el gobierno del presidente George W. Bush.

Al amparo de la "cruzada" emprendida contra el "terrorismo internacional", el gobierno del presidente Bush ha impulsado determinadas iniciativas de ley que han impuesto sensibles restricciones a la libertad de expresion y a los derechos relativos a la intimidad de las personas. El inventario de iniciativas impulsadas por el gobierno de Bush que limitan el acceso a la información y la privacidad de los ciudadanos comprende: "Wiretap Statute, Electonic Communications Privacy Act", "Computer Fraud and Abuse Act", "Foreign Intelligence Surveillance Act", "Family Education Rights and Privacy Act", "Pen Register and Trap and Trace Statute", "Money Laundering Act", "Immigration and Nationality Act", "Money Laundering Control Act", "Bank Secrecy Act", "Right to Financial Privacy Act", "Fair Credit Reporting Act", "USA Patriotic Act" y la Anti-Terrorism Act 2001 (ATA).

${ }^{10}$ Véase http://www,epic.org/privacy/terrorism/usapatriot/ Fecha de consulta: 23 de agosto, 2003. 
Tales iniciativas han propiciado efectivas prácticas de censura y de autocensura en los medios informativos estadounidenses. En la invasión y ocupación de Irak, por ejemplo, en repetidas ocasiones Donald Rumsfeld, secretario de Defensa de Estados Unidos, se abrogó la facultad de censurar la transmisión de determinadas imágenes a través de las cadenas de televisión estadounidense.

Internet había permanecido como una especie de territorio indómito a las pretensiones de control informativo de la administración del presidente Bush, quien en repetidas ocasiones ha insistido en la necesidad de "terminar con la anarquía que prevalece en Internet". A partir del 11 de septiembre de 2001, el gobierno del presidente Bush decidió intensificar la vigilancia de la información que circula a través de Internet. Para ejercer efectivas funciones panópticas ${ }^{12}$ sobre la información que circula a través de Internet, el gobierno del presidente Bush ha impulsado la adecuación del marco normativo correspondiente. La "USA Patriotic Act", por ejemplo, concede amplias facultades a las áreas de seguridad del gobierno de Estados Unidos para inspeccionar la información que circula en Internet, e inclusive les autoriza interceptar todas aquellas comunicaciones que consideren "sospechosas". Para tal propósito el FBI (Federal Bureau of Investigation) ha desarrollado un efectivo sistema que permite espiar la información que circula a través de Internet: "carnivore".

Para el desarrollo, coordinación e implementación de una estrategia integral para la protección de los Estados Unidos, la administración Bush creó la Oficina de Seguridad Nacional. Esa Oficina coordina los esfuerzos de detección, preparación, prevención, protección, respuesta y recuperación de ataques terroristas dentro del territorio estadounidense. ${ }^{13}$ Una de las iniciativas que ha impulsado la Oficina de Seguridad Nacional para extender sus funciones panópticas, es el sistema CAPPS II (Computer Assisted Passenger

"Véase Gerardo Albarrán de Alba: "EU: La doble moral informativa". Sala de Prensa. Número 54. http://www.saladeprensa.org/art433.htm Fecha de consulta: 24 de agosto, 2003.

${ }^{12}$ Internet efectivamente admite ser empleado como un medio susceptible de desempeñar útiles funciones de "buen encauzamiento". A través de las diferentes herramientas de comunicaciones de Internet es posible realizar una vigilancia jerárquica, aplicar sanciones normalizadoras y exámenes. Tales actividades representan el fundamento mismo del panoptismo Véase Michel Foucault (1983): Vigilar y castigar. Nacimiento de la prisión. México, Siglo XXI Editores.

${ }^{13}$ Véase "Homeland Security Actions". Disponible en línea en: http:ll www,whitehouse.gov/homeland/Fecha de consulta: 16 de agosto, 2003. 
Pre-Screening) -Preinspección de Pasajeros Asistida por Computadora-. El sistema CAPPS en realidad funciona desde 1998, y procede de los atentados terroristas que se registraron durante el desarrollo de los juegos Olímpicos de Atlanta, en 1996, así como del trágico desenlace del vuelo 800 de la compañía TWA, el cual se estrelló en el Océano Pacífico a consecuencia de un "desperfecto mecánico".

El sistema CAPPS I empleaba la información que almacenan las aerolíneas al registrar a los pasajeros, y comprendía información relativa a los viajes realizados así como los posibles antecedentes delictivos de los pasajeros. De acuerdo con Linda Ackerman, activista de la organización Privacyactivism, hasta la fecha no se sabe con certeza cuántas personas han sido detenidas gracias al sistema CAPPS I, pero es seguro que éste no precisamente fue un impedimento insalvable para quienes perpetraron los ataques terroristas del $11 \mathrm{de}$ septiembre de 2001.

De acuerdo con información publicada por la Transportation Security Administration (TSA), en el sistema CAPPS II se han incorporado un mayor número de variables que en el sistema anterior, y además a través de CAPPS II es posible tener acceso a bases de datos comerciales, las cuales concentran información que definitivamente admite ser considerada como privada, pues comprende los estados financieros de los pasajeros, los datos registrados en el padrón electoral, e inclusive historiales médicos y de seguros.

CAPPS II funciona de manera relativamente similar a CAPPS I. A cada pasajero le es asignado un código de seguridad durante su registro en la aerolínea: verde para aquella persona que sea considerada como un pasajero susceptible de representar un riesgo mínimo; amarillo (alerta) para quien se considere capaz de generar algún problema abordo; y rojo para aquella persona que sea considerada como peligrosa. En función de cada código que sea asignado a cada pasajero variaría sensiblemente el proceso de revisión: "Delta Airlines fue la primera empresa en experimentar con el sistema CAPSS II. Para abordar un avión cada pasajero tenía que registrar nombre, dirección, y fecha de nacimiento, posteriormente el personal de la empresa podía realizar una revisión del historial crediticio, aparentemente por cuestiones de seguridad".'

14 Véase PrivacyActivism. Disponible en línea en: http:ll www.privacyactivism.org/Item/48 Fecha de consulta: 16 de agosto, 2003.

${ }^{5}$ Véase Pierce D: Law \& Technology: CAPSS IIT The Seattle Press. Disponible en línea en: http://www.seattlepress.com/article-10116.html Fecha de consulta: 16 de agosto, 2003. 
Linda Ackerman destaca cuatro aspectos críticos en la implementación del Sistema CAPSS II. El primero se relaciona con la información contenida en cada base de datos; el segundo corresponde a la creación de perfiles digitales de presuntos terroristas; el tercero involucra el tema de las libertades civiles; y el cuarto corresponde a la búsqueda de procedimientos alternativos de seguridad no intrusivos.

\section{a).- La confiabilidad de la información}

Uno de los principales problemas del panóptico digital CAPSS II, es la confiabilidad de las fuentes de información. Ackerman afirma que las bases de datos públicas y privadas en promedio presentan un $30 \%$ de errores -ya sean errores de captura, modificaciones o bajas del registro-, lo cual implicaría que de cada diez pasajeros tres podrían enfrentar incalificables atropellos por errores en la información almacenada en los registros.

Además ninguna base de datos en línea es completamente segura: "El CAPPS II afectará a los 100 millones de personas que viajan cada año (...) Aún en el caso de que el sistema tuviera una proporción de aciertos del 99.9 por ciento, habría 100,000 errores al año".'

\section{b).- Los perfiles}

La criminalística estadounidense le confiere particular relevancia a las metodologías fundamentadas en la investigación de perfiles (profiles). Se afirma que con la implementación de "redes neuronales", el "sistema nervioso digital" admite la capacidad de poder predecir con base en el reconocimiento de determinados patrones de aprendizaje. Sin embargo, algunas organizaciones dedicadas a la defensa de los derechos humanos, atinadamente han denunciado que la elaboración de perfiles digitales a partir de información privada de los ciudadanos, sin contar su consentimiento expreso, definitivamente representa una práctica ajena a la ética.

De acuerdo con el periódico La Jornada, la agrupación Privacy International, la cual se dedica a la investigación de abusos en materia de privacidad, otorgó hace dos años a la empresa ChoicePoint el

${ }^{16}$ Véase R. ¿Despegará el plan de seguridad en los aeropuertos? Disponible en línea en: http://us.terra,wired,com/wired/politica/0,1156,23188.00.html Fecha de consulta: 15 de julio, 2003.

${ }^{17}$ Véase B. Gates: (1999): Business @ the speed of thought. Using a digital nervous system. USA. Warner Books. 
premio "Big Brother" por la "venta masiva de expedientes precisos e imprecisos, a policías, compradores directos y funcionarios electorales".' De acuerdo con los periodistas Jim Cason y David Brooks, ChoicePoint otorgó a los responsables electorales de Florida, datos sobre votantes que no podían tener derecho de sufragar en la elección presidencial de Estados Unidos en el 2000: "miles de registros fueron depurados del padrón con base en esta información. Fue un escándalo político al ser revelado, ya que los comicios presidenciales fueron definidos por las irregularidades y el conteo tan cerrado, precisamente en ese estado".

El sábado 12 de abril de 2003, la agencia noticiosa Associated Press (Estados Unidos) reveló que ChoicePoint [http:// www.choicepoint.com] compró nuestro padrón electoral. Un vocero de la referida compañía afirmó que además adquirieron los registros de licencias para conducir de seis millones de habitantes del Distrito Federal. De ese modo, mientras que en Estados Unidos la empresa ChoicePoint vende al mejor postor información contenida en el padrón electoral mexicano, en México esos datos son considerados por ley como confidenciales.

Los productos y servicios que ofrece ChoicePoint se encuentran divididos en 9 grupos: Pre-employment Services, Direct Marketing Services, Public Records Information, P\&C Insurance Underwriting Services, P\&C Insurance Claims Services, Comercial Insurance Services, Fingerprint Solutions, Authentication Solutions, y Financial Solutions. ${ }^{2}$ Los principales clientes del área de "Public Records Information" son agencias federales, estatales y locales (Estados Unidos), el Federal Bureau of Investigation (FBI), la Drug Enforcement Administration (DEA), y el U.S. Inmigration \& Naturalization Service (INS).

Entre las empresas que colaboran con ChoicePoint en el desarrollo del "Centro para la Investigación Social y Legal" (Center for Social \& Legal Research) figura Microsoft, propiedad del amigo y generoso benefactor Mr. Bill Gates, quien ha destinado considerables sumas de dinero y recursos para el desarrollo del Sistema Nacional e-México

18

Carson, J., Brooks, D.: "ChoicePoint la hace de Big Brother para Washington" / La Jornada Disponible en línea en: http://www,jornada.unam.mx/ 006nlpol.php?origen=index,html Fecha de consulta: 16 de agosto, 2003.

${ }_{20}^{10}$ Ibidem.

${ }^{20}$ Véase: http://www.choicepoint,net/industry/all products.html Fecha de consulta: 23 de agosto, 2003. 
como para las actividades "altruistas" de la señora Marta Sahagún de Fox. En el referido centro se realizan investigaciones relativas al tema de los "registros públicos y al uso responsable de la información". Ademán en las actividades del referido centro participan otras 18 empresas, entre las cuales destacan: American Expresss, Citigroup, America Online, Bell Atlantic, CyberCash, IBM, MCI Communications, News Corporation, Internet Alliance. El centro se encuentra a cargo del Dr. Alan F. Westin, profesor emérito de la Columbia University.

¿Qué interés podría tener el gobierno de Estados Unidos en la información contenida en el Padrón Electoral de los Estados Unidos Mexicanos y en los registros de licencias para conducir de seis millones de habitantes del Distrito Federal?. En el documento "Uniting and Strengthening America by Providing Appropiate Tools Required to Intercept and Obstruct Terrorism -conocido como USA Patrotic Actes posible encontrar la respuesta. ${ }^{21}$ Por cierto, en el sitio WWW de ChoicePoint, en la sección "Productos y Servicios", y dentro del rubro "Soluciones Financieras", es posible encontrar un curioso apartado: "US Patriot Act Compliance".

\section{c) Las libertades}

De acuerdo con organizaciones dedicadas a la defensa de los derechos humanos, como American Civil Liberties Union, Privacy Activism y la Association of Corporate Travel Executives, sistemas como CAPPS II representan una amenaza a la privacidad de las personas y son contrarios a los principios establecidos en la Declaración Universal de los Derechos Humanos.

De acuerdo con esos organismos, el gobierno del presidente Bush no ha garantizado que la información privada que han confiado los ciudadanos estadounidenses a sus autoridades, no será usada indebidamente, y tampoco ha informado cómo funcionará el sistema CAPPS II ni cómo podrían prevenirse posibles errores. Estos son algunos de los principales cuestionamientos:

${ }^{21}$ El documento puede ser consultado en el sitio WWW del Electronic Privacy Information Center (EPIC). Además se encuentra disponible en PDF. Véase: http:/ /www,epic.org/privacy/terrorism/hr3162 Fecha de consulta 23 de agosto, 2003.

Véase: http://www.choicepoint.net/industry/all products.html Fecha de consulta 23 de agosto, 2003.

${ }^{23}$ El artículo 12 de La Declaración Universal de los Derechos Humanos establece: «Nadie será sujeto a una interferencia arbitraria en su privacidad, familia, hogar o correspondencia». 
- ¿Qué tipo de información personal puede manejarse como información de dominio público?

- ¿Qué garantías de seguridad podrán tener las personas cuyo registro aparezca en el CAPPS II?

- ¿Quién vigilará a los vigilantes del sistema?

- ¿Con qué instituciones podrá compartirse la información contenida en el CAPPS II?

- ¿Cuánto tiempo quedará almacenada la información de pasajeros con código amarillo o rojo?

Éstas son algunas de las preguntas que tendrá que responder el Congreso de los Estados Unidos antes de autorizar la implementación del sistema.

\section{d) La no intrusión}

Para Ackerman el sistema CAPPS II no representa la mejor solución a los costosísimos problemas de seguridad que enfrentan las aerolíneas. Cualquier solución no puede pasar por encima de las libertades civiles.

\section{La respuesta de la sociedad civil}

Ryan McKinley, investigador del famosísimo Media Lab del MIT, ha desarrollado un sistema denominado "Government Information Awareness" (GIA), el cual admite ser considerado como una efectiva respuesta ciudadana a iniciativas panópticas digitales de los gobiernos, como es el caso del "CAPPS II". La iniciativa GIA parte de un sencillo razonamiento: "Si el gobierno tiene derecho a conocer detalles personales de los ciudadanos, los ciudadanos también tienen el derecho de conocer información crítica de sus gobiernos".

El objetivo de McKinley es desarrollar tecnologías amigables que permitan a los ciudadanos desarrollar sus propias agencias de inteligencia para obtener, clasificar y actuar con base en la información que logren obtener de sus gobernantes. GIA permitiría que el ciudadano común y corriente se ocupara de documentar asuntos de interés público, como la información relativa al financiamiento de las campañas electorales, la curricula de los funcionarios públicos, documentar la existencia de denuncias, las relaciones secretas o confidenciales de los grandes corporativos, información que ha sido 
clasificada y hasta un sistema para la construcción de perfiles basado en el estudio de patrones.

Figura 3 Página Principal del proyecto Government Information Awareness

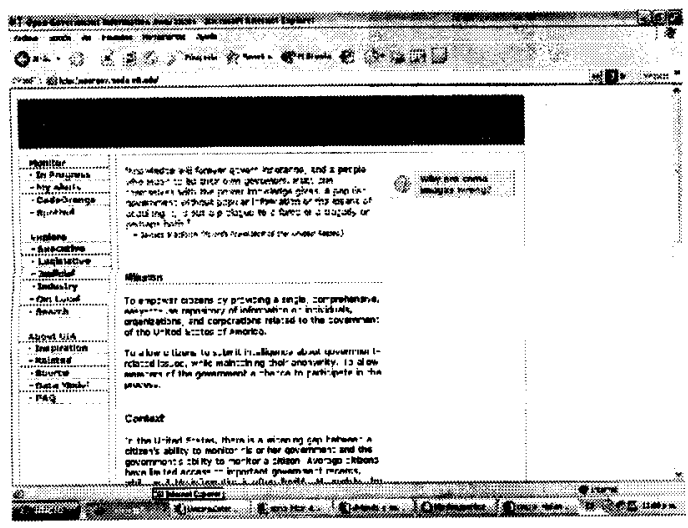

Fuente: Government Information Awareness

http://opengov.media.mit.edu/

GIA definitivamente no admite ser considerada como una iniciativa aislada, pues forma parte de las imaginativas respuestas que ha empezado a articular la sociedad civil para revertir algunos de los negativos efectos que desplaza consigo el panoptismo digital. En esta compleja búsqueda es posible ubicar el desarrollo de los "weblogs".

El viernes 21 de marzo de 2003, el periodista Kevin Sites, de la cadena Cable News Network (CNN), anunció desde su Weblog [ www.kevinsites.net/» http://www.kevinsites.net/] que por presiones del medio informativo para el cual laboraba (CNN) se veía en la necesidad de interrumpir en Internet la labor noticiosa que venía desempeñando en el desarrollo de la invasión a Irak. En respuesta Edna Johnson, publicista de CNN afirmó: "La cobertura para CNN es un trabajo de tiempo completo y le hemos pedido que se concentre en eso exclusivamente".

${ }^{24}$ Véase M. Melio: "Government Prying, the Good Kind". En Wired. Disponible en línea en: http://www.wired.com/news/privacy/0.1848.59495.00.html Fecha de consulta: 16 de julio, 2003

${ }^{25}$ Véase X. Jardín: San Luis Obispo New Times. 4 de abril de 2003 Disponible en línea en: http://dashes.com/kevinsites/ Fecha de consulta: 16 de abril, 2003. 
Como resultado de la censura impuesta por $\mathrm{CNN}$, un significativo número de cibernautas expresó su abierta indignación a través de correos electrónicos. Tales acciones sorprendieron a los directivos de la referida cadena de noticias, quienes efectivamente no alcanzaban a comprender las posibilidades informativas de los "Weblogs". En un principio los "Weblogs" fueron concebidos como, sistemas estructurados en Internet que permitían que cualquier usuario de Internet publicara información personal de forma similar a un diario, con la capacidad de registro de direcciones electrónicas, inclusión de imágenes, e interacción asíncrona. Sin embargo, los "Weblogs" rápidamente evolucionaron hasta convertirse en auténticos periódicos digitales, en los cuales es posible encontrar distintos puntos de vistas sobre un evento particular. Los "Weblogs" hoy compiten en Internet con los medios informativos convencionales que han prolongado su presencia al ciberespacio.

En el marco de la guerra en Irak, los "Weblogs" representaron una de las principales fuentes de información de los cibernautas. En algunos "Weblogs" fueron consignados impresionantes testimonios del drama que padecieron los iraquíes, galerías fotográficas de personas que cubrían de forma independiente la movilización bélica, imágenes de video que se actualizaban minuto a minuto, discusiones y opiniones sobre el conflicto expresadas por personas de todo el mundo, y direcciones electrónicas de sitios WWW que proporcionaban informacịón relativa a la guerra. Rápidamente los "Weblogs" fueron reconocidos como "Warblogs" -sitios independientes en Internet con información de cualquier tipo concerniente a la guerra-.

Entre los "Warblogs" más importantes destacan:

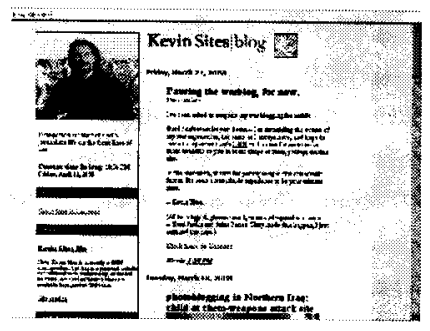

[http://www.kevinsites.net] Kevin Sites Blog

Se trata del sitio de Kevin Sites, controvertido corresponsal de CNN. La última actualización corresponde al 21 de marzo de 2003, por las razones antes referidas. En ese sitio es posible encontrar interesantes entrevistas grabadas en formato de audio digital e imágenes del frente de guerra. 


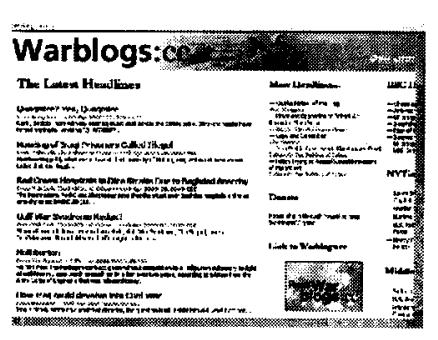

[http://warblogs.cc/]

Warblogs:cc

Es uno de los sitios más visitados por la calidad y diversidad de la información que presenta sobre el conflicto en Irak, la cual comprende noticias consignadas en los principales diarios, agencias de noticias y "blogs" independientes. El sitio lo mantienen los "bloggers": Christopher Allbritton, George Paine, Sean-Paul Kelley y Mike Hudack.

\section{http://www.back-to-iraq.com/] Back to Iraq 2.0}

Es el "Warblog" de Christopher Allbritton, reportero de la agencia de noticias AP y del periódico New York Daily News, que incluye foros de discusión, calendario de mensajes, motor de búsqueda, ligas a otros "blogs" y un sistema de pagos para la recepción de donativos. Allbritton señala que a través de su página ha recibido más de $\$ 10,000$ dólares en donativos.

[http://www.tacitus.org/] Tacitus Sitio desarrollado por un veterano del

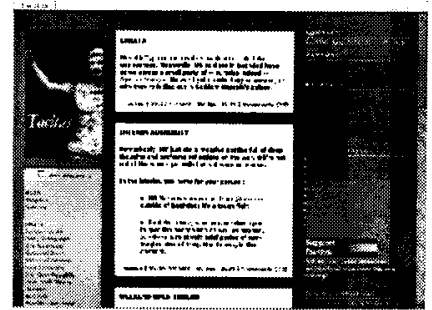
ejército de Estados Unidos, que ofrece un espacio abierto para la discusión sobre "las acciones de un imperio en consolidación". El sitio incluye calendario de mensajes, noticias actualizadas de diferentes fuentes, y referencias a otros "blogs". El autor afirma que su propósito es documentar las acciones de guerra de una nación., tal como lo hizo Cornelius Tacitus, célebre historiador romano. 


\section{[http://www.agonist.org/] The Agonist}

"Blog" mantenido por Sean Paul Kelley, el cual cuenta con más de un

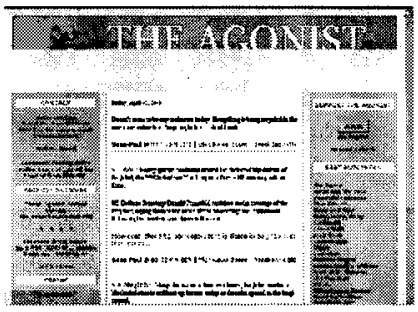
millón y medio de visitas desde el inicio de la guerra y ocupación de Irak. El sitio contiene un acervo histórico de noticias de guerra y una interesante clasificación de otros "Blogs" que presentan información relativa al conflicto. Además dispone de un sistema de transferencia de donativos que permite la operación del "Blog".

Otros interesantes "Warblogs" son:

Warblogging [http://www.warblogging.com/], Stand Down [http:/l www.nowarblog.org/], Daily Kos [http://www.dailykos.com/], Talk Left [http://www.talkleft.com/], Where is Raed? [http:// www.dear raed.blogspot.com/], y World-War-Three [http://worldwar-three.com/ww3/].

El atractivo de los "Warblogs" radica en la inmediatez y espontaneidad de la información, así como en la narrativa misma de los eventos. Los cibernautas acuden a esos espacios porque en ellos esperan encontrar distintas posiciones sobre un tema en particular, derivándose así la confrontación o el diálogo, el cual, de acuerdo con Mariano Amartino: "evita la exposición de ideas y tiende a formar comunidades que interactúan en tiempo real".

En el marco de la guerra y ocupación de Irak han irrumpido distintas clases de "Warblogs", como "Blogs" de corresponsales de prestigiadas cadenas noticiosas; de soldados; de familiares de los soldados; de grupos activistas; de iraquíes; de simpatizantes de la resistencia iraquí; de pacifistas; y por supuesto, "Blogs" de "Blogs".

La diversidad de visiones y versiones representa uno de los aspectos más atractivos del emergente medio. Muchos cibernautas consideran que el "Warblogger" -el administrador del "Blog", diario

${ }^{26}$ Véase M. Amartino: Breve historia de los weblogs, la ola que le cambió la cara a la red 11 de febrero de 2003 Disponible en línea en: http:ll weblogs.clarin.com/conexiones/archives/000018.html Fecha de consulta: $16 \mathrm{de}$ abril, 2003 
o bitácora dedicada a la información relativa a la guerra-, puede ofrecer una visión del conflicto mejor que aquélla que presentan los medios informativos convencionales o los mismos sitios WWW de medios que han extendido su cobertura informativa al ciberespacio. Los detractores de los "Warblogs" afirman que la información que consignan los improvisados en asuntos propios de profesionales de la información solo produce confusión.

Sin duda alguna es posible establecer una relación directa entre el instantáneo éxito alcanzado por los "Warblogs", y las iniciativas emprendidas por el gobierno del presidente Bush destinadas a restringir la libertad de expresión y los derechos relativos a la intimidad de las personas, al amparo, por supuesto, de la "cruzada emprendida por el gobierno de Estados Unidos, dispuesto a combatir al terrorismo internacional".

Voceros del gobierno de Estados Unidos han desacreditado a los "Warblogs", argumentando que en la abundante información que ofrecen resulta difícil distinguir lo efectivamente relevante. Es justo reconocer que pensadores como Jean Baudrillard han afirmado que Internet crea un mundo "invivible" para el hombre, quien finalmente resulta incapaz de poder soportar toda la responsabilidad histórica que se desprende de la abundante información que recibe. Por otra parte, también es justo señalar que el gobierno de Estados Unidos desacredita los "Warblogs" pues en éstos publican información que no puede controlar. ${ }^{2 f}$ De acuerdo con Baudrillard, el rol del "gatekeeper" (filtrador de información), resulta indispensable en la era de "La Sociedad de la Información". Sin la mediación del "gatekeeper", el individuo ordinario que no ha desarrollado las habilidades necesarias para analizar información será desbordado por la abrumadora cantidad de información que cada día es posible consultar en Internet.

De acuerdo con la firma Net Ratings (Nilsen), el número de usuarios de Internet que suelen visitar sitios dedicados a proporcionar noticias en línea ha registrado un sensible crecimiento. Durante el año 2002, por ejemplo, 67.5 millones de cibernautas visitaron ese tipo de espacios informativos. Hoy se estima que el número de usuarios de Internet que con regularidad visitan esos sitios asciende a 80

${ }^{27}$ Jean Baudrillard expresó tales argumentos en el IV Congreso Internacional de la Federación Iberoamericana de Semiótica, evento realizado por la Universidad de La Coruña, España, el 7 de octubre de 1999. 
millones. ${ }^{28}$ A consecuencia de la exitosa proliferäción de los "Blogs", algunos medios de comunicación convencionales que prolongaron su trabajo informativo a Internet han optado por imitar estrategias de comunicación observadas por los "Blogs".

El acceso a la información ya no es privilegio exclusivo del periodista. "Los Weblogers pueden convertirse en la mayor red de corresponsales locales que ningún grupo mediático puede poseer jamás".

El lado oculto de "la Sociedad de la Información y el Conocimiento" es la "sociedad de la uniformidad, la vigilancia y el castigo". Del uso histórico que demos a las avanzadas tecnologías información dependerá la calidad de vida que nos depare la "Sociedad de la Tercera Ola". Manuel Castells advierte:

"Si las leyes de control y vigilancia sobre Internet y mediante Internet son aprobadas por una clase política que sabe que el control de la información ha sido siempre, en la historia, la base del poder, las barricadas de la libertad se construirán tecnológicamente. Pero es aún más importante que las instituciones de la sociedad reconozcan y protejan dicha libertad... Ni Internet es una red de libertad, en un mundo en que la tecnología puede servir para el control de nuestras vidas mediante su registro electrónico, ni la tendencia al control ubicuo es irreversible". ${ }^{30}$

\section{BIBLIOGRAFÍA}

ALONSO, A. y ARZOZ I (2002): La nueva ciudad de Dios. Un juego cibercultural sobre el tecno-hermetismo, Madrid, Siruela. AGUILAR Camín, H (1989): Después del milagro. México.

${ }^{28}$ Véase M. Ostrom: Net plays big role in war news, commentary, $28 \mathrm{de}$ febrero, 2003. Disponible en línea en: http://www.siliconvalley.com/mld/ siliconvalley/5285029.htm Fecha de consulta: 16 de abril, 2003.

${ }^{29}$ Véase "El valor de los Weblogs": Citado en Caspa.tv Disponible en línea en: http://www,caspa.tv/archivos/cat weblogs.html Fecha de consulta: 16 de abril, 2003.

${ }^{30}$ Véase Manuel Castells: Internet: ¿una arquitectura de libertad? Libre comunicación y control del poder. Disponible en línea en: http://www,forumglobal,de/soc/bibliot/castells/internetlibertad.htm Fecha de consulta: 28 de agosto, 2003. 
Editorial Cal y Arena.

AUGÉ, M. (1992): Los no lugares. Espacios del anonimato. Una antropología de la sobremodernidad, Barcelona, Gedisa.

BARRET, N. (1998): El estado de la cibernación, España, Ediciones Flor del viento..

BARTOLOMÉ Cresco, Donaciano (Coord.) (1991): Estudios sobre tecnologías de la información, España, Editorial Sanz y Torres.

BAUDRILLARD, J. (1989): Crítica de la economía política del signo, México, Siglo XXI.

BAUDRILLARD, J. (1995): La ilusión del fin. La huelga de los acontecimientos, Barcelona, Anagrama.

BECK, U./ GIDDENS, A./ LASH, S. (1994): Modernización reflexiva. Política, tradición y estética en el orden social, Madrid, Alianza.

BICKERTON, P. Et al (2000): Ciberestrategia, México, Prentice may.

CASTELLS, M. (1997): La era de la información. Economía, sociedad y cultura (Vol. 1: La sociedad red). México, Madrid, Alianza.

CEBRIÁN, J. (1998): La red, España, Taurus.

CHOMSKY, N. (1997): Secretos, mentiras y democracia. Entrevista a Noam Chomsky por David Barsamian. México. Siglo XXI Editores.

CONTRERAS, F. y SAN NICOLÁS C. (2001): Comunicación, diseño gráfico, creatividad y comunicación, Madrid, Blur Ediciones.

CORRRALES C. (1987): El significado sociocultural de las nuevas tecnologías de comunicación. En Cuadernos Huella, número 14, México, ITESO.

DABAS, E./ DENSE, N. (2000): Redes. El lenguaje de los vínculos, Argentina, Piados.

DAVARA M. (2000): De las autopistas de la información a la sociedad virtual, España, Aranzadi Editorial.

DAVIS, S. Y MEYER, C. (1999): Blur the speed of change in the connected economy. New York, Warner Books.

DE KERCHOVE, D. (2000): Inteligencias en conexión, España, Gedisa.

ECO, U. (1968): Apocalípticos e integrados, España, Lumen.

ECHEVERRÍA, J. (1994): Telépolis, Barcelona, Destino.

ELGUEA, J. (1994): Telecomunicaciones y desarrollo, México, 
Intelmex

FEATHETSTONE, M. / BURROW, R. (1995): Cyberspace, cyberbodies, cyberpunk. Cultures of technological embodiment, London, Sage.

FERNÁNDEZ, F. (1986): "Nuevas tecnologías de información en México". Ponencia presentada en el III Encuentro CONEICC, Guadalajara, Jalisco, 1984, México, UAM Xochimilco.

FERNÁNDEZ, F. (1985): "Génesis del Sistema de Satélites Morelos. De proyecto privado a programa estatal". En Información Científica y Tecnológica, número 100, México, CONACYT.

FERNÁNDEZ, F. (1986): “Nuevas tecnologías y política”. Ponencia presentada en el V Encuentro Latinoamericano de Facultades de Comunicación Social.

FORESTER, T. (1991): Sociedad de alta tecnologia, México, Siglo veintiuno editores.

FOUCAULT, M. (1983): Vigilar y castigar. Nacimiento de la prisión. México, Siglo XXI Editores.

FUKUYAMA, F. (2000): La gran ruptura, Barcelona, Ediciones B.

FUKUYAMA, F. (1994): El fin de la historia y el último hombre, Barcelona, Planeta de Agostini.

GATES, B. (1999): Business @ the speed of thought. Using a digital nervous system. USA, Warner Books.

GIL, P. (2000): E-Formation, París, Dunod.

HABERMAS, J. (1993): Ciencia y técnica como ideología, México, REI.

HAMELINK, C. (1981): La aldea trasnacional, España, Gustavo Gili.

HEILBRONE, R. (1995): Visiones del futuro, España, Piados.

HOLZ, H. (1998): The consultant's guide to getting business on the Internet, USA, John Wiley \& Sons, Inc.

ISLAS O, y GUTIÉRREZ, F. (2000): Internet. El medio Inteligente. México, CECSA.

ISLAS O, y GUTIÉRREZ, F. (2002): Explorando el ciberperiodismo lberoamericano. México. CECSA.

ISLAS O, y GUTIÉRREZ, F. (2002): .com probado. México. CECSA.

JAMESON, F. (1984): El posmodernismo o la lógica cultural del capitalismo avanzado, Barcelona, Paidós.

JAMESON, F. (1991): Teoría de la postmodernidad, Madrid, 
Trotta.

JONAS, H. (1979): El principio de responsabilidad. Ensayo de una ética para la civilización tecnológica, Barcelona, Herder.

JONAS, H. (1992): Pensar sobre Dios y otros ensayos, Barcelona, Herder.

JOYANES, L. (1997): Cibersociedad. Los retos sociales ante un mundo digital, España, McGraw Hill.

KELLER, L. (1995): Cybermarketing. New York, Amacon.

LA ROSA, A (2001): "Investigación de la comunicación y autopistas de la información". En Comunifé, revista de comunicación social, número 1, Perú, Universidad Femenina del Sagrado Corazón.

LANDOW, G. (1998): Teoría del hipertexto, España, Piados.

LEMOS, A, y MARCOS P. (2000): Janel@s do ciberspaco, Brasil, Editora Sulina.

LEMOS, A. (2002): Cultura das redes, Brasil, Edufba

LINARES, J. ORTIZ, F. (1995): Autopistas inteligentes. Madrid, España. FUNDESCO.

LUHMANN, N. (1991): Sistemas Sociales. Lineamientos para una teoría general. México. Alianza Editorial-Universidad Iberoamericana.

LULL, J. (1995): Media, communication, culture. A global approach. USA, Columbia University Press.

MARQUES, J. (1984): “La investigación latinoamericana en comunicación”. En Chasqui, número 11, Ecuador. CIESPAL.

MARQUES, J. (1987): "Teoría e investigación de la comunicación en América Latina: balance preliminar de los últimos 25 años". En Estudios sobre las culturas contemporáneas, vol. 1, número 2, México.

MARTÍN BARBERO, J. (1978): De los medios a las mediaciones: comunicación, cultura y hegemonía, México, Gustavo Gili.

MATTELART, A. (1977): Multinacionales y sistemas de comunicación: los aparatos ideológicos del imperialismo, México, Siglo XXI.

MATTELART, A. y SCHMUCLER, H. (1983): América Latina en la encrucijada telemática, México, Folios.

McLUHAN, M. (1977): La comprensión de los medios como extensiones del hombre, México, Editorial Diana.

McLUHAN, M. y POWERS, R .(1991): La aldea global, México, Editorial Gedisa. 
MOLES, A (1986): La imagen, México. Trillas:

NAVARRO, L. (2002): Los periódicos online, México, Universidad Autónoma de San Luis Potosí.

NEGROPONTE, N. (1996): Ser digital, México, Océano.

NORRIS, C. (1990): ¿Qué le ocurre a la posmodernidad? La teoría crítica y los límites de la filosofia, Madrid, Tecnos.

NOZICK, R. (1997): Puzzles socráticos, Madrid, Cátedra.

PISCITELLI, A. (1995): Ciberculturas. En la era de las máquinas inteligentes, España, Piados.

PRIETO, D. (1982): "Educación, tecnologías y futuros". En Chasqui, segunda época, número 5, Ecuador, CIESPAL.

PRYSTHON, A. (2002): Cosmopolitismos periféricos, Brasil, Edicoes Bagaco.

PRYSTHON, A, et al. (2002): Interferencias contemporáneas comunicao, estudos culturais epós-moderno, Brasil, Edicoes Bagaco.

QUEU, P. (1996): Lo virtual. Virtudes y vértigos, España, Piados. RIVELLI, C. (2000): Intelligence stratégique sur Internet, París, Dunod.

RORTY, R. (1991): Objetividad, relativismo y verdad. Escritos filosóficos I, Barcelona, Paidós.

RHEINGOLD, H. (1997): La comunidad virtual, España, Gedisa. RICHERI, G. (1984): El universo telemático, España, Editorial Mitre.

SÁNCHEZ, A. (2001): La Era de los afectos en Internet, México, Océano.

SÁNCHEZ DE ARMAS, M. (1998): Comunicación y globalidad. Ensayos de ecología cultural, México, Fundación Manuel Buendía.

SANTACRUZ, L. (1993): Comunicación satelital y desarrollo, México, Fundación Manuel Buendía.

SARTORI, G. (1998): Homo videns. La sociedad teledirigida, España, Taurus.

SCHILLER, H. (1976): Comunicación de masas e imperialismo yanqui, España. Gustavo Gili.

SFEZ, L. (1986): Critique de la Communication, París, Seuil.

SHIELDS, R. (1998): Cultures of Internet, London, Sage. SIEGEL, D. (1997): Secrets of successful web sites, USA, Hayden Books.

TANCENBAUM, A. (1997): Redes de Computadoras, México, Ed. 
Prentice-Hall.

TELEVISA (1979): II Encuentro Mundial de Televisión. La Edad de la Televisión. México.

THESING, J. y PIESS, F. (1999): Globalización, democracia y medios de comunicación, Argentina, Konrad Adenauer StiftungCIEDLA.

TOFFLER, A (1981): La tercera ola. México. Edivisión.

TREJO R. (1994): La nueva alfombra mágica. Usos y mitos de Internet. La red sin redes, México, Los Libros de Fundesco.

TREJO R. (1997): Volver a los medios. De la crítica a la ética, México, Ediciones Cal y Arena.

VERNE, J. (2000): Obras Selectas, España, Edimat Libros.

VILLANUEVA, E. (1998): "Límites jurídicos de la libertad informativa en la red de redes». En El Nacional, Suplemento Medios, número 3, p. IV, 12 de abril.

VILLANUEVA, E. (2000): Hacia un nuevo derecho de la información. México, Universidad Iberoamericana-Konrad Adenauer Stiftung.

VILLANUEVA, E. ( 2000): Derecho mexicano de la información, México, Oxford.

WANG, C. (1996): Tecnovisión, México, McGraw-Hill.

WHITAKER, R. (1999): El fin de la privacidad. Cómo la vigilancia total se está convirtiendo en realidad, Barcelona, Paidós, WOOOLLEY, B. (1992): Virtual Worlds, London, Peguin Books. ZEFF, R, y ARONSON, B. (1997): Advertising on the Internet, USA, Wiley Computer Publishing.

ZOBEL, R. (1998): Business transformation through technology, Amsterdam, European Commission. 